\title{
A RESPONSABILIDADE AMBIENTAL \\ Uma leitura medieval paradigmática: Redução das Ciências à Teologia de S. Boaventura
}

Joaquim Cerqueira Gonçalves*

\begin{abstract}
SINTESE - Em nossa época, a ciência e a técnica foram endeusadas e passam agora a ser olhadas como suspeitas, ante a degradação cada vez maior do planeta. Nossa civilização herdou o conceito grego de ciência e de técnica. Na Idade Média, houve propostas diferentes de considerá-las, tentando vê-las em um conjunto harmônico e não de forma estanque. $O$ melhor modelo desta forma diferente foi o de Boaventura, em seu trabalho $A$ reduçäo das ciências à Teologia.
\end{abstract}

\begin{abstract}
Science and technics in our times were deified, but now they are seen as suspect, on account of the continuous degradation of our planet. Both concepts our civilization has herited from the Greeks. In the Middle Ages they were considered harmonically, not separately, as Saint Bonaventure did it.
\end{abstract}

1. A degradação do ambiente provocou um capítulo novo na especulação hodierna, se é que não se transformou em a questão da nossa época, atraindo a si todos os saberes, inclusive 0 da ética, que se julgava de aplicação exclusiva à esfera humama.

Com efeito, a responsabilidade ultrapassou, em termos de aplicação, o âmbito dos seres pessoais, deixando estes de constituir a referência única dos deveres humanos. Vai-se falando já do direito dos animais, pressagiando esta tendência um código ético-jurídico da terra. Tal sucedeu porque esta passou a ser, em muitos aspectos e lugares, inabitável e ultrajada, prevendo-se que tal situação se possa agravar no futuro. É assim que a humanidade dos nossos dias se vê obrigada a interrogar-se sobre a sua própria responsabilidade no desequilibrio do nosso planeta, que pode bloquear a continuidade da existência.

Sempre houve um sentimento de responsabilidade nesse campo, mas ela ou era muito esbatida ou se equacionava em parámetros diferentes. De facto, as calamidades diluvianas ou afins, pelas quais a terra, até mesmo o universo, se anulavam nas suas formas especificamente constituidas, regressando ao estado de caos indefinido, é um tópico frequente nos textos das diversas culturas. Trata-se, porém, de um aniquilamento que é consequência dos decretos da justiça divina, pe-

- Universidade de Lisboa.

\begin{tabular}{|l|l|l|l|l|l|}
\hline VERITAS & Porto Alegre & v. 40 & $\mathrm{n}^{2} 159$ & Setembro 1995 & p. $453-468$ \\
\hline
\end{tabular}


rante os desatinos morais dos seres humanos, e não o resultado da própria ação destes. Hoje, a situação alterou-se radicalmente: é já a humanidade, e não a Divindade por causa dela, que directamente destrói, seja mediante o poder técnico de que dispõe, seja por exercer incorrectamente a sua função no universo.

2. No entanto, o referencial da ética tem-se imposto com dramática premência, se não em relação ao que se encontra negativamente perpetrado, ao menos como aposta de, por esse meio, salvar o que resta. Porque o processo de destruição se agiganta, dia a dia, excedendo as previsões e as capacidades humanas de o controlar, estabeleceu-se, em estilo de recurso desesperado, o regresso aos imperativos éticos, obrigando-se, desse modo, a humanidade a prescrever um limite ao seu próprio fazer. A ciência e a técnica, que pareciam constituir infalíveis instâncias derradeiras de orientação e de moderação racionais, eliminando todos os apelos a outros foros, vêem-se agora excedidas, em resultado dos destroços que semearam, depois de se ter esperado delas utópicos benefícios.

A solução ética pareceria simples, se o saber ético representasse também uma instância autónoma e última. Não será, todavia, que se vem transferindo para ele a responsabilidade e espontânea bondade que eram, até há pouco, atribuidas à ciência e à técnica? Substituindo a ciência e a técnica pela ética, não se permanecerá no mesmo plano, donde não parece ser de aguardar soluções positivas radicais? Se não se afigura viável resolver os problemas com que a sociedade hodierna se debate, pelo simples aperfeiçoamento da ciência e da técnica, como se as dificuldades que provocaram se devessem apenas ao estado imperfeito daquelas, também não parece que a ética, mesmo se for excelente, possa ser arvorada em panaceia eficaz.

O que se vai impondo, a diversos títulos, é a urgência de uma reformulação de ordem epistemológica, ora promovendo um olhar diferente sobre a ciência, ora regressando a filosofemas que se haviam eclipsado, como o da articulação e classificação do saber. Através desta, seria ao menos possivel discutir se as instâncias em que nos temos instalado, como a da ciência, da técnica e da ética, são verdadeiramente originárias ou se, pelo contrário, carecem de ulterior fundamentação.

3. Disseminou-se quase epidemicamente a ideia de que a ciência e a técnica são as exclusivas e demoníacas protagonistas do estado actual de degradação da terra. Nesse contexto, pássou-se ora a rejeitar a ciência e a técnica, ora a exigir destas uma alteração substancial, de modo a torná-las factores operacionais benéficos. O recurso à ética situa-se na complexa rede de todo este processo, julgandose sobretudo que ela poderia orientar criteriosamente a aplicação da ciência e da técnica, atenuando, assim, as possiveis consequências maléficas destas, raciocinando-se, deste modo, que a tecnociência é entidade neutra, cuja bondade ou malefício não the são intrínsecos, mas dependem dos critérios da sua aplicação.

Esta argumentação, porém, umas vezes sentida, outras vigorosamente proclamada, parece ser sintoma de um errado diagnóstico da situação, particularmente no que concerne ao peso da interferência dos diversos factores em presença, em especial os de índole tecnocientifica. 
Há, com efeito, boas razões para se duvidar do papel absoluto da ciência e da técnica, pelo que, por essa razão, também não se afigura coerente atribuir-lhes radicais responsabilidades na degradação do ambiente. Urge, então, porventura averiguar o que condiciona a própria ciência e a técnica. Mas esta diligência aparentase difícil, depois de se haver acolhido, ao menos tacitamente, a ideia de que a ciência é a grande expressão da cultura, podendo mesmo reduzir-se esta àquela. Ora, o que tem de ser deslindado é o caminho que levou a tal redução, no qual se tem movimentado, com oracular solenidade, o chamado iluminismo moderno, outrora um mar de promessas e hoje um oceano de desilusões.

4. Mais do que se afirmar que a modernidade é a época da ciência e da técnica, deve-se, antes, esclarecer que os tempos modernos levaram ao máximo expoente a cultura científica e técnica, percebendo-se, desde logo, pelo contraste, que a ciência e a técnica, substantivas, na primeira formulação, se metamorfoseiam em forma adjectiva na segunda. A ser assim, o que se impõe, uma vez mais, é o esclarecimento dessa transformação. Por outras palavras, urge deslindar por que razão a cultura - que é substantiva - ocidental foi decisivamente marcada pela ciência e pela técnica, permitindo que estas, não só se substantivassem, mas ainda passassem a substituir a própria cultura, de que são meras expressões, relativamente recentes, ao lado de outras, talvez não menos importantes do que elas.

A razão mais funda da situação degradada do nosso planeta parece, efectivamente, situar-se no solo das opções fundamentais da cultura ocidental, as quais, pelo facto de serem da ordem da cultura, não são marcadas por qualquer insuperável fatalismo, de modo a barrar o caminho a quaisquer outras alternativas. Mas sendo a cultura uma manifestação de racionalidade, é por isso legitimo pretenderse saber quais os motivos dessas opções, entre muitas outras possíveis e mesmo quiçá realizadas em outras culturas.

Não se pode, contudo, chegar aos pródromos últimos e infinitos dessa explicação, até porque nunca se pode decifrar a cultura saindo fora das suas malhas. Teremos de começar sempre pelas nossas cercanias, por aquilo que sentimos estar germinalmente arraigado em nós. Sem condescendermos com a ideia fixa de que tudo tem a ver com a aleitação dispensada no berço helénico, a referência a ele, contudo, se bem não tão primigénio como se julga, pode ser ponto de pertinente clarificação. Pelo menos, no que à ciência diz respeito, as preocupações da cultura grega não podem ser olvidadas, dada a força da sua presença na história da cultura ocidental.

Com efeito, não obstante o reconhecimento da pertinência do esquema que traduz a tensão entre a tendência apolínea e a dionisíaca nessa cultura helénica, somos obrigados a registar, ao menos a partir de um certo momento, a vitória do mental, a que fica reduzida a realidade, a identificar com a transparência do mundo do pensamento. É verdade que a epistemologia grega, no modo como interpretava o saber, não se fixava na descrição do real, lançando-se, antes, na sua transformação, mas apenas na medida em que esta representava a redução de tudo a uma suposta consistência mental. Era já o iluminismo ocidental a germinar, assumindo a 
tarefa de salvar a realidade do caos, pela redução dela a uma racionalidade pura ou, se se quer, pela transformação da ontologia em lógica.

Mas também este processo não foi obra do acaso. A cultura grega não via razões para a existência do múltiplo, procurando a luz possivel, embora minguada, para a sua irrecusável existência, no esquema de degradação, a partir de uma unidade, isenta de quaisquer diferenças, à qual importaria fazer tudo regressar. 0 exercício da ciência representava ainda uma situação imperfeita de multiplicidade, mas era já um conseguido expediente para a anulação do múltiplo individual. Se houve razões, aliás nem sempre plausiveis, para se contrastar a razão e o mito, os dois se encontram, neste ponto, já que tanto um como outro procuram debelar o mal, o da própria multiplicidade.

Sem se pretender identificar a especulação grega com as tendências maniqueístas, a História reconhece que elas se encontraram, não sendo, por outro lado, fácil escamotear os seus múltiplos factores de convergência. Pelo menos, Filosofia e maniqueísmo instrumentalizaram-se reciprocamente. A cultura ocidental passou a ser um rio com múltiplos afluentes, mas, nas águas deste, podem ser registrados ingredientes de coloração afim: uma realidade sem sentido, a que urgia conferi-lo, mediante a imposição sobre ela de formas mentais, que o exercício do saber possibilitava, assumindo, desse modo, a ciência uma função soteriológica, a de diluir o múltiplo na universalidade.

Trata-se, simultaneamente, de uma ciência e de uma técnica, tudo se processando automaticamente, já porque só o pensamento pode outorgar sentido, já porque, e por outro lado, o mal, por ser mais vasto e radical do que a vontade humana, à qual eventualmente se poderia imputar, não depende desta, se é que, em tal contexto, de vontade livre se poderá falar. Entre outros motivos, a gnose cristã distanciou-se da gnose pagã exactamente pela ausência, nesta última, da dimensão da vontade, de que resultava um automatismo no processo de libertação. Significará o apego da sociedade contemporânea à técnica apenas uma adesão à eficácia desta ou deverá ser antes explicável por mecanismos anímicos e culturais mais profundos?

5. A Idade Média recebeu os vectores da cultura antiga e, não obstante as inflexões que o cristianismo neles introduziu, o quadro epistemológico antigo, por carecer de alternativa, foi acolhido quase integralmente, embora com arranjos diversificados, por vezes muito significativos.

O horizonte medieval, contudo, era já outro, conseguindo mesmo penetrar no que se considerava mais consistente, universal e necessário, ou seja, nas próprias estruturas do saber. Com efeito, este, não tendo agora as mesmas funções, passava também a ser interpretado, no que à sua própria natureza, não tanto à sua forma, dizia respeito, em moldes muito diferentes. É verdade que Santo Agostinho, autor dos grandes princípios hermenêuticos do cristianismo latino, ao pretender salvaguardar a consistência da liberdade pessoal, ameaçada sobretudo pelo formalismo e pela astrologia, apelou para o cogito, podendo favorecer, desso modo, as prioridades do universo mental, mas tal risco não se concretizou, ao menos nessa época, tendo até relativizado, como nunca se fizera antes, o saber, fragilizando também al- 
gumas expressões cientificas, que pareciam definitivamente intocáveis. ${ }^{1}$ Reconheça-se, entretanto, o enfraquecimento da natureza daí resultante, devido à absorção nas preocupações do sujeito, situação que os medievais do século XIII, mesmo os de cariz agostiniano, teriam de alterar.

Mas o que deve ser realçada, na Idade Média, é a integração do saber nas grandes coordenadas da mundividência cristã, que não esgotam certamente a medievalidade, tida em consideração, sobretudo, a presença árabe e judaica, mas a caracterizam, de forma indelével, mesmo quando em emaranhados cruzamentos, de que não está ausente o maniqueísmo.

Dito em termos globais, o novo espírito incutido à cultura de estirpe greco-romana pelo cristianismo é, contudo, de profunda orientação anti-gnóstica e antimaniqueia. Neste contexto, mesmo com a persistência dos quadros epistemológicos antigos, decisivas alterações se tornavam inevitáveis. A realidade múltipla - as criaturas, na terminologia de inspiração biblica - é acolhida positivamente, não precisando de ser transformada, pelo facto de ser negativa, mediante a intervenção do espírito humano, merecendo até ser contemplada, na luz que lhe é intrínseca, e desenvolvida, pelo ser humano, de modo livre e histórico. Com efeito, não se trata já de enfrentar, com a ciência, o espectro ontológico do múltiplo, do mal, que excederia a vontade do ser humano, mas, sim, de potenciar as virtualidades da criação, que pedem, pela constituição da sua própria natureza, a colaboração dos entes livres e inteligentes, aliás pertença do mesmo mundo e envolvidos por idêntica destinação.

A terem vencido culturalmente estas amplas coordenadas cristãs, dificilmente se poderia ter chegado à situação actual do nosso planeta, cuja degradação só pode ser explicada pela interferência destruidora de quem não lhe encontra sentido e não o ama, exactamente o que sucede na mundividência maniqueista e gnóstica, que, por isso, dele se distancia, ou transferindo-o para uma suposta unidade indiferenciada originária ou, na impossiblildade desta via, atenuando os factores dissolventes da multiplicidade, pela constituição de uma universalidade racional, veiculada em todas as expressões científicas.

Não são propriamente a ciência e a técnica as causas - próximas ou remotas da situação que ora vivemos, mas, antes, as tendências mais profundas da cultura ocidental, de proveniência grega, maniqueia e gnóstica, de que a ciência e a técnica modernas são apenas consequência, se bem não inocentes e neutras para qualquer aplicação.

\section{II}

6. Sendo a cultura um domínio radical e abrangente, a sua expressão é múltipla e onipresente, não sendo fácil apreender as mais significativas coordenadas duma cultura em obras específicas. A atmosfera da cultura tudo invade, sem que

1 A ânsia de certeza de Contra Academicos não impede Agostinho, antes o estimula, de rejeitar e condenar algumas ciências do seu tempo, algumas das que haviam sido feitas por mãos de homens, supersticiosas e supérfluas (De Doctrina Christiana II, 25). De qualquer modo, o cogito agostiniano, não obstante a sua função precursora, no âmbito gnosiológico, relativamente à modernidade, tende mais a salvaguardar a liberdade do que a certeza. 
se veja esgotada no que quer que seja, embora se manifeste sempre por determinações. Por outro lado, vamo-nos apercebendo progressivamente da complexidade da cultura medieval, em que qualquer tentativa de síntese não pode esquecer a presença de intermináveis factores. Restam a intuição e a opção do intérprete, que não têm aliás de ser necessariamente aleatórias. Dentro do nosso modo de diagnosticar a actual degradação ambiental e pensando em termos de etiologia significativa e determinante, a nossa atenção dirige-se privilegiadamente para a ciência, a técnica e a ética, não para nos fixarmos no terreno destas, mas para denunciarmos as razões da proeminência, um tanto ou quanto artificial, delas, pressentindoas nas raizes da cultura ocidental. Esta situação, por sua vez, espontaneamente ou por contraste, remete-nos para um pensador medieval de recursos e interesses polifacetados, representando, em todo o caso, um privilegiado reflexo dos vectores da medievalidade. Referimo-nos a S. Boaventura e, entre.a sua volumosa obra, ao opúsculo Reductio artium ad theologiam, ${ }^{2}$ onde aflora o questinamento ontológico, epistemológico e ético, que consideramos obrigatório para a abordagem da crise ambiental.

Lembremos que S. Boaventura é um universitário do século XIII, que se tornou membro de uma ordem mendicante, a Ordem Franciscana, de que foi aliás responsável máximo, ocupando, nessa função, o $7^{\circ}$ lugar, na sucessão do fundador da mesma, S. Francisco de Assis.

Enquanto universitário, repercutiu-se nele, não apenas a tradição da herança cristã, tendencialmente agostiniana, mas já também a recente presença de numerosas obras da sabedoria greco-romana; como franciscano, interpreta a mundividência da sua época, incontornavelmente irredutível à que informou a vida dos séculos passados, embora estes não tenham sido menos cristãos. De salientar, para. os nossos propósitos, a missão peculiar das recém-fundadas ordens mendicantes, Dominicanos e Franciscanos, na oposição às tendências neomaniqueístas grassantes, no seu tempo, cátaros e albigenses, entre outros movimentos mais representativos.

Fundamentalmente, Boaventura vai pronunciar-se sobre a unidade - a de Deus, a do mundo, a do ser humano, a das ciências - fazendo-o, contudo, em termos bem diferentes dos que haviam sido adoptados quer pela especulação grecoromana, quer pelas doutrinas maniqueístas e gnósticas, residindo aí uma das notas peculiares da sua mundividência cristã e franciscana.

Redução das Ciências à Teologia é um texto, onde se sente a mão de teólogo e de filósofo, melhor dito, de um homem de cultura, familiarizado com controversas questões do seu meio, sobre a vida e sobre o saber, perante as quais toma lúcida e serena posição, ainda nesse opúsculo.

7. A questão da classificação dos saberes não é inédita. Ela é mesmo inerente a todo o saber que procura a unidade, perante uma irrecusável diversidade. Boaventura não exibe novos saberes nem sequer desconhecidos quadros e esquemas

2 Redução das Ciências à Teologia, Trad. Not. e Int. de Ilídio de Sousa Ribeiro, Ed. Atlântida, Coimbra, 1948. 
científicos. ${ }^{3} \mathrm{O}$ que é digno de nota, nele, são as incidências, as preocupações e o estilo das análises levadas a efeito. $O$ saber não aparece aí como um aparelho autónomo e imune das contingências da vida, ao contrário que pensaram muitos contemporâneos nossos, embora em vias de superação. É, antes, marcado pelos traços característicos da mundividência que o inspira, contrastando com aquela que conduziu ào estabelecimento do estatuto dos saberes na Grécia. Para o Doutor Seráfico, o número e a natureza das ciências integradas no quadro por ele assumido é suficiente e adequado, representam um facto que, não sendo embora de valor $a b$ soluto, não merece discussão. ${ }^{4} \mathrm{O}$ Doutor Seráfico comporta-se, neste acolhimento dispensado às ciências até então reconhecidas, com a confiança e serenidade de um pensador grego. $\mathrm{O}$ que ele não aceita, de forma contundente, se bem serena, ao contrário de numerosos contemporâneos seus, sobretudo membros da Faculdade das Artes, é a autonomia avulsa de cada um desses saberes, já por falta de comunicação entre eles, já por se fecharem à transcendência.

8. Mas se um dos propósitos fundamentais é, como o título por que é mais comumente conhecido o opúsculo sugere, ${ }^{5}$ não apenas a introdução da Teologia nesse quadro, como também, senão sobretudo, a ordenação de todos os saberes a ela, o modo como todo este processo é conduzido introduz um horizonte filosófico e teológico muito caracteristico, onde todos os elementos em presença ganham um sentido verdadeiramente novo.

Se a classificação das ciências procura, acima de tudo, a unidade, dependências e colaboração entre elas, não vai estar fora das intenções bonaventurianas essa preocupação, mas que não é conseguida à semelhança do que se passou na filosofia greco-romana, além de tal unidade não se opor à diversidade dos saberes, constante e positivamente realçada por Boaventura. ${ }^{6}$

3 O quadro das ciências de Redução das Ciências à Teologia è de Hugo de S. Vitor, como ele reconhece, no $\mathrm{n}^{2}$ 2: "[...] quas assignat Hugo in Didascalico [...]." São hoje conhecidas múltiplas classificações medievais, de interesse indiscutivel para a compreensão das mundividências das diversas fases dessa época. Os saberes mantêm-se, na sua globalidade, os mesmos, mas os diversos arranjos revelam, näo apenas uma atitude relativista e versátil do pensador medieval perante a ciência, como também uma enorme liberdade na utilização e instrumentalização das ciências. Boaventura é, neste aspecto, mais respeitador do fundamental estatuto epistemológico delas do que muitos outros medievais que 0 antecederam e ele sucederam.

4 É muito assumida pelo Doutor Seráfico, no opúsculo, esta doutrina da sufficientia das ciências que adopta, parecendo formular um princípio metodológico ocamista, o de não multiplicar sem necessidade, embora a multiplicidade dos saberes não seja menos acentuada por Boaventura.

De facto, o opúsculo foi conhecido sob diversos títulos: "De luminibus sive de ortu scientiarum", "Tractatus de divisione scientiarum", "Sermo bonus et utilis", "Sermo de septem artibus mechanicis", etc., apreendendo-se, nesta pluralidade, uma diversidade de interpretações e utilizações do texto.

Logo no início do opúsculo: "In hoc verbo tangitur origo omnis illuminationis, et simul cum hoc insinuatur multiplicis luminis ab illa fontali luce liberalis emanatio "( $\left.n^{2} 1\right)$. E no fim:"Et sic patet, quomodo multiformis sapientia Dei [...]." (n 16$)$. O Doutor Seráfico é um dos grandes misticos cristäos, sendo de esperar dele uma forte tendência para a união, o que realmente sucede. A união, contudo, nunca é conseguida com sacrificio da diferença dos entes, sobretudo os de dignídade pessoal. É por isso que a presença do Pseudo-Areopagita na sua obra tem de ser interpretada com circunspecçäo. Boaventura refere-se a ele $\left(n^{2} 5\right)$ ao estabelecer o elenco das grandes figuras cristăs que representaram as diversas perspectivas cristäs, atribuindo a S. Dionísio, como ele próprio se exprime, a uniäo, acrescentando, quase de imediato, que as iluminações desta vida, as da ciência, terão ocaso, melhor dito, serão substituidas pela iluminação da glória ( $\left.n^{2} 6\right)$. 
Numa primeira e desprevenida leitura, a teologia de Redução das Ciências à Teologia identificar-se-ia com a teologia cristã, a chamada teologia positiva, para a distinguir, desse modo; da teologia natural. Era esse certamente o sentido que Boaventura pretendia conferir-lhe, no entanto, essa teologia cristã é mais do que um saber construído somente a partir do texto bíblico, não obstante a fidelidade evangélica conscientemente assumida pelo franciscanismo. A Teologia, como todo o saber, é uma interpretação, onde a fidelidade ao ponto de partida não exclui nem o enriquecimento historicamente logrado nem o investimento activo do intérprete. É por isso que a teologia bonaventuriana não é já a de Santo Agostinho. Por outro lado, pesem embora as clivagens de ordem epistemológica, muito activas na época do Doutor Seráfico, relativas à fonte natural ou revelada do conhecimento, que aliás o opúsculo supõe e tenta superar, a unidade vivenciada entre o cristão e o homem natural daquele tempo representa um dado espontâneo, pelo que falar aí de um equivale a supor o outro. ${ }^{7}$ o que fundamentalmente Boaventura vai mostrar é que toda a actividade cognoscitiva conduz a Deus, visto toda a acção, presente em todos os entes, se processar dentro da mesma estrutura, que tem no Deus trinitário a acção das acções - a sua semelhança.

A especulação à volta da unidade, desenvolvida em Redução das Ciências à Teologia é, por isso, a chave para o entendimento de toda a especulação bonaventuriana. Com efeito, a realidade, seja ela qual for, é marcada pela mesma estrutura de manifestação. Trata-se de uma entidade dinâmica, que em todos os entes se revela do modo idêntico, exprimindo cada um deles a sua imagem, num esquema ternário de princípio, meio e fim. ${ }^{8}$ Dir-se-á que se trata da aplicação, de certo modo artifical, senão mesmo arbitrária, porque decorrente de uma opção de fé, do modelo da Trindade cristã a todo o movimento da realidade. Mas esta objecção tem uma limitada pertinência. Deveria acrescentar-se que a novidade não reside nesta visão expressionista da realidade, de fundas raízes neoplatónicas, mas, sim, na especificação trinitária cristã dela, que muitos séculos de vivência e especulação teológica e antropológica, tenha-se em vista o característico texto agostiniano,

7 A distinção entre natural e sobrenatural é comum a todos os grandes pensadores medievais, embora não entendida da mesma forma, insistindo uns na oposição e outros nas afinidades, podendo considerar-se o Doutor Seráfico entre estes últimos, pelo que não admira ele veja em toda a actividade criada o esquema de acção da própria Trindade, que a Escritura consigna.

8 Pensando constantemente por analogias, Boaventura associa o que considera o conteúdo essencial da Escritura - geração etema, incarnação de Cristo e a união da alma com Deus ( $\left.n^{2} 5\right)$ - com a causalidade aristotélica: "[...] assim como em Deus, ser supremo, deve considerar-se a razão de causa eficiente, de causa formal ou exemplar e de causa final [...]" ( $\left.n^{\circ} 4\right)$. Ou ainda, referindo-se às ciências: fisica, que se ocupa das causas do ser, lógica, cujo objecto são as razões de entender, e a moral, ocupando-se da norma do viver (Ibidem). Eis um exemplo sugestivo, no âmbito do conhecimento sensitivo:o órgão, o meio e o objecto $\left(n^{2} 3\right)$. O seguinte texto, ainda referido ao mesmo tipo de conhecimento, é uma elucidativa síntese de todo este processo ontológico:" $\mathrm{E}$ ainda que nem sempre 0 objecto seja sentido, contudo gera sempre a sua semelhança quanto de si depende, quando está em plenitude. Por este modo hás-de, bem assim, entender que da inteligência suprema, que é cognoscivel pelos sentidos interiores da nossa mente, emanou deste toda a etemidade a sua semelhança, que é ao mesmo tempo imagem e prole" ( $\left.n^{2} 8\right)$. Repare-se na função activa dos objectos, dos entes materiais, no exercício cognoscitivo, tal como é activa, na linha da gnosiologia agostiniana, presente em Boaventura, a sensação. 
De Trinitate, legitimaram com certa naturalidade. De facto, não há teologias e filosofias naturais, visto serem todas filhas das contingências da cultura. ${ }^{9}$

A unidade, de que fala o Doutor Seráfico, é inerente a cada ente individual, irredutível a qualquer outro, não representando, de modo algum, a unidade abstracta quer da espécie quer da ciência que, por esse expediente, esvaziaria a consistência ontológica dos indivíduos, para os expor, sem relutância, às manipulações mecanicistas. Por outro lado, ao contrário da natureza e função da unidade, na especulação grega, a unidade bonaventuriana é um foco de vida diferenciada e diferenciadora, manifestando-se por determinaçöes múltiplas, não pretendendo salvar, por anulação destas, mas, antes, desenvolver. Desde logo fica vincado esse carácter de difusão gratuita e generosa da unidade de cada ser, que vive para promover e nunca para reduzir a si a vida dos outros. Além disso, essa manifestação ontológica generosa não se realiza por desordenada intumescência, que acabaria por reduzir, inquinando-a, toda a realidade à sua unicidade teratológica, difundindo-se, pelo contrário, ordenadamente: um principio gerando a determinação de um meio, ganhando este peculiar tematização especulativa em um dos filosofemas fundamentais de Boaventura, o exemplarismo. ${ }^{10}$

Se a nota de generosidade ontológica de cada ente garante a não-supressão dos outros, evitando a sua redução a meros objectos, o movimento de relação recíproca dos diversos entes afirma ainda mais o sentido do desenvolvimento quer da globalidade quer de cada ente. Com efeito, a unidade diferenciada não deve ser vista apenas em cada indivíduo, mas também na ordenação global de todos eles, desde as criaturas materiais, sempre qualitativamente consideradas, até Deus. Uma unidade de semelhança atravessa toda a realidade, ${ }^{11}$ resultando dai que o movimento de expressão de um tende a revelar a riqueza virtual, historicamente concretizada, do outro. ${ }^{12}$

A redução, que representa outra chave de interpretação do opúsculo, revestese na especulação bonaventuriana de características inconfundiveis. Ela não reduz o que quer que seja a outrem, menos ainda em jogos dialécticos entre sujeitos e

9 Tanto pode ser afirmado que Boaventura transfere os modelos bíblicos para a natureza como os desta para a Bíblia: "Et ideo sacra Scriptura frequenter talibus similitudinibus utitur satis recte" (n²14).

10

0 exemplarismo tem múltiplos alcances na especulação bonaventuriana, sendo também uma chave de compreensão em Redução das Ciências à Teologia: Representa a nota mais clara da diferenciação ontológica, a começar pela própria Trindade; confere uma tonalidade ontológica à causa formal aristotélica; traduz a consistência da determinação do que é gerado por expressão. Através dele se vê também, pelo facto de ocupar o meio, como a aç̧ão supöe três termos e não apenas dois, ficando assim acautelada a possiblidade de redução de um ao outro, por exemplo em esquema de sujeito/objecto, caso o esquema fosse apenas dual. Santo Agostinho que, numa primeira fase, entendia a vida do amor numa relação dual, reconheceu, mais tarde, ser-lhe necessário o esquema temário (De Trinitate VIII, 10, 14). Com o realce do meio, o que conhece não usurpa o objecto alheio, dirá Boaventura $\left(n^{2} 9\right)$. O exemplarismo exercerá também, no campo da retórica, uma função importante, pois, entre o que profere a palavra e o ouvinte, interpöe-se o conteúdo ( $\left.n^{2} 15\right)$, a verdade, diria Agostinho, em De Doctrina Christiana, distanciando-se, assim, da retórica romana pagã.

11 Há semelhança entre o Pai e o Filho, na Trindade, entre o órgão dos sentidos e dos elementos, entre esse mesmo órgão e o objecto (ns 3, 8).

12 O Doutor Seráfico bem pode ser considerado filósofo e teólogo da História, ao movimento da qual ele aplicará também o esquema temário, que vimos referindo. A ênfase posta na historicidade manifesta também a consistência da obra realizada e o valor da multiplicidade. 
objectos, apontando, antes, a direcção da fonte energética, donde podem incessantemente nascer novas e imprevisíveis possibilidades, dada a sua inesgotável capacidade de diferenciação, imprimindo sempre um movimento de vida, onde cada um assume a função de princípio, meio e fim, relativamente a todos os outros. ${ }^{13}$

9. Mas onde melhor se pode ver este processo de manifestação ontológica, até porque esse é o propósito de Redução das Ciências à Teologia, é na actividade gnosiológica, na qual, como temos insistido, costumam disfarçar-se as coordenadas negativas e perversas da cultura ocidental.

Firme no horizonte de unidade, Boaventura terá de interpretar a actividade cognoscitiva como expressão de vida ontológica, a instância mais radical a que a unidade, no opúsculo, se situa. Por isso, todos os saberes se exprimem do mesmo modo, embora em graus diferentes. O Doutor Seráfico alonga-se, dentro do reduzido espaço desse texto, na descrição desse esquema ternário de manifestação, percorrendo todos os saberes por ele assumidos. ${ }^{14}$

Fica desde logo claro que o saber é não só constitutivo do ser humano, como é por ele que este se relaciona privilegiadamente com os demais entes, que aliás aspiram a serem elevados na sua escala ontológica, pelo exercício gnosiológico, colaborando eles activamente no processo, em vez de se deixarem manipular pela redução a objectos inertes de ciência. Boaventura que, a muitos títulos, poderia ser considerado um pensador de tendência platónica, acolhe uma boa parte da gnosiologia da abstracção aristotélica, embora conciliando-a com a iluminação agostiniana, para, desse modo, afirmar a relação constitutiva do ser humano com o mundo.

A activịdade gnosiológica, porém, tal como a vida da unidade, tem, repita-se, uma função muito diferente da que foi reconhecida pela epistemologia antiga. Não se processa, mediante ela, nem uma fuga do mundo, por ensimesmamento do sujeito humano ou por aniquilação da diversidade, nem a negação de sentido à realidade, como se fosse dele destituido e precisasse de o receber da mente humana. Pelo contrário, a toda a realidade é inerente o sentido, não fosse ela constituída por luz, ${ }^{15}$ podendo, entretanto, esse sentido ser intensificado pela acção reciproca dos entes, particularmente pela intervenção humana, que se manifesta sobretudo pelo

13 Por vezes, a terminologia bonaventuriana parece cúmplice do círculo neoplatónico de processão e retorno, falando mesmo de egressus e de regressus ( $n^{2} 23$ ). No entanto, o processo de redução é bem mais complexo, precisamente pela insistência no meio:"Em primeiro lugar, diz-se recto aquilo cujo meio não excede os extremos. Ora, sendo Deus a rectidåo suma, não só em si mesmo considerado, mas também enquanto é princípio e fim de todas as coisas, necessariamente há-de colocar-se em Deus uma pessoa intermédia de sua mesma natureza, de modo que deva distinguir-se Nele uma pessoa que só é produtora, outra somente produzida e uma intermédia, produtora e produzida ao mesmo tempo. É igualmente necessário colocar um meio na produção e no retomo das coisas criadas; mas é indispensável que este meio se aproxime mais do producente e, no retorno, se aproxime mais do que retoma" ( $\left.n^{2} 23\right)$.

14 É este um dos desígnios mais sensiveis do opúsculo, mostrando, desse modo, o valor do exercicio da ciência, a sua não-nocividade, superando hesitações de muitos séculos cristãos, e ainda, senão sobretudo, confirmando a vantagem da mesma ciência, a manifestação de Deus nessa mesma actividade.

15 A terminologia das iluminações parece não dever ser alheia a preocupação no reconhecimento do sentido da realidade, mas também o grande horizonte da metafisica da luz, que facilitava enormemente a visão de uma estrutura unitária da mesma realidade. 
conhecimento. Este, como já foi acentuado, é uma operação de caracteristicas ontológicas, obedecendo, portanto, ao esquema fundamental de manifestação, difundindo-se pela produção da sua semelhança e relacionando-se com os outros, também por semelhança.

10. Vale a pena exemplificar esta actividade ontológica em alguns dos saberes presentes no quadro adoptado por Boaventura: a arte mecânica (liuz exterior), o conhecimento sensitivo (luz inferior) e o conhecimento filosófico (luz interior) e, neste, o conhecimento ético. ${ }^{16}$

É significativa a referência à actividade exercida no conhecimento dos objectos artificiais, característica das artes mecânicas, que disfruta de direito de cidadania na classificação do saber, a respeito da qual Boaventura não denuncia qualquer escrúpulo. Também nele se realiza, não apenas o ser humano, mas também o próprio mundo. ${ }^{17}$ Tal conhecimento é mesmo privilegiado, em termos pedagógicos, para exibir o esquema ontológico fundamental: a geração e incarnação - atente-se no valor da matéria - a norma de viver e a união ${ }^{18}$ Representa, por um lado, uma actividade, gerando o seu meio e procurando realizar a melhor obra possível. Logra-se, assim, mediante ele, a união do ser humano com a realidade, ao mesmo tempo que esta fica engrandecida, pela excelência da obra produzida. Note-se, desde já, que, sendo uma instância ontológica, nela emerge sempre a norma de viver, a instância onde a ética se enraíza, ${ }^{19}$ contribuindo, assim, a ciência "[...] para a beleza da obra, a vontade para a sua utilidade e a perseverança para a sua dura-

16 Boaventura apresenta o quadro das ciências de vários modos: luz exterior da arte mecânica, luz inferior do conhecimento sensitivo, luz interior do conhecimento filosófico e luz superior da Sagrada Escritura $\left(n^{2} 1\right)$. Esta divisão quadripartida é, no entanto, aumentada para seis, pelo desdobramento do conhecimento filosófico: "Do que fica dito se conclui que, embora consoante a primeira divisão seja quádrupla a luz que descende do alto, são contudo seis as partes em que esta se diferencia, a saber:a luz da Sagrada Escritura, a luz do conhecimento sensitivo, a luz da arte mecânica, a luz da filosofia racional [lógica], a luz da filosofia natural [física, matemática e metafisica], e a luz da filosofia moral.

17. Também esta ciência da arte mecânica a refere Boaventura a Hugo de $S$. Victor $\left(n^{2} 2\right)$, considerando-a destinada à recreação (teatro) e comodidade (agricultura e caça, etc.), deleitando e suprindo indigências (Ibidem). 0 que deve, no entanto, ser realçado é o valor da obra elaborada, que o artista realiza o melhor possivel, de tal modo que "[...] se o efeito conhecesse o seu autor, certamente o faria;e se esse efeito conhecesse o seu autor, isto só poderia dar-se por meio daquela semelhança à imitação da qual procedeu o artífice" ( $n^{2} 12$ ). Essas produções são como as que se assemelham a Deus, enquanto vestígios e imagens ao qual chegam por conhecimento e amor (Ibidem). Deste modo, a actividade de produção de obras artificiais, por de actividade se tratar, é semelhante à dos seres naturais.

18 Nas artes mecânicas deve atender-se à produção, ao efeito è ao fruto dessa arte, ou seja, ao trabaIhar, à qualidade do efeito produzido pela arte e à utilidade do fruto obtido, cuja semelhança com o objecto fundamental da Escritura, a geração e a incamação do Verbo, a norma do viver e a unição de Deus e da alma, é fácil de apreender. Repare-se particularmente no valor da incarnação, de grande alcance teológico e também cultural, pois virá dignificar toda a realidade material.

19 A valorização da obra produzida ocupa uma posição nuclear neste opúsculo, não se assemelhe ela ao Verbo gerado e incamado da Trindade. É por isso que a qualidade da sua produção é essencial à conduta moral do ser humano. As características que a obra deve ter - bela, útil e duradoira - correspondem ao "[...] saber, querer e obrar de modo inabalável ou com perseverança" ( $\left.n^{2} 13\right)$. Fica, assim, aproximada a acção prática da acção poiética, que os pensadores gregos, de certo modo, distanciaram, a favor da primeira. Esta perspectiva bonaventuriana é de flagrante pertinência para 0 esclarecimento de uma filosofia da técnica. 
ção" ${ }^{20}$ Além da nota estética do processo, assinale-se o prazer do artifice na obra realizada, bem como a união com ela e com Deus, que toda a actividade propicia. ${ }^{21}$ Boaventura está muito longe dos pessimismos actuais decorrentes da chamada alienação técnica. Esta não tinha, no seu tempo, não obstante ser considerado, por vezes, o início da era industrial, ${ }^{22}$ o gigantismo que atingiu nos nossos dias, mas os perigos que agora the são imputados poderiam ser enormemente esbatidos se a técnica não estivesse entregue a si própria, destituída de enquadramento ontológico e ético.

Também o conhecimento sensitivo merece cuidada atenção de Boaventura, que vê nele, tal como em todo o exercício cognoscitivo, uma actividade, a qual, dir-se-ia, é sempre positiva, desde que não constitua disfarçada passividade. Por ele se processa a relação do ser humano com o mundo, uma vez mais mediante a semelhança, já que aos cinco elementos correspondem os cinco sentidos do corpo humano, como a tradição vinha estabelecendo. ${ }^{23}$ Tal como em toda a actividade e, em particular, na de características gnosiológicas, nele se manifesta o meio, o exercício de conhecer e o prazer concomitante a este exercício, num encontro de radical bondade ontológica, onde dificilmente penetram hesitações de cepticismo agudo ou de reduções mecanicistas. Sendo tal conhecimento uma actividade, não degenera, não obstante nela interferir a realidade sensivel. Trata-se de uma actividade, sendo, por isso, sempre generosa, nada sacrificando, intentando sempre o de-

20 "Scientia reddit opus pulchrum, voluntas reddit utile, perseverantia reddit stabile" ( $n^{2} 13$ ). Não deixa de surpreender a insistência de Boaventura na estabilidade e duração da obra, sobretudo se se pensar no seu horizonte de pobreza, que tinha particular ênfase na vida franciscana. O Doutor Seráfico, contudo, pensa em total coerência: a construção humana do mundo - o meio gerado pela acção não é provisória, mas também não é definitiva, na medida em que vai progredindo. $O$ espirito de pobreza reside na não-usurpação dela pelo egoísmo do seu autor, que deve evitar o que é nocivo, vencer a concupiscência, não usurpar o alheio, triunfando, assim, da soberba ( $n^{\circ} 9$ ). Mais do que de uma interpretação moral da actividade técnica, trata-se aqui da integração ontológica desta, remetendo-a, por redução, para a fonte de toda a acção, na qual toda a actividade dos seres criados participam, recebendo-a como um dom. É uma forma de aproximar o fazer do agir, o que, a suceder, conferirá ao primeiro um valor indiscutivel.

21 "[...] nada há nela [na arte mecânica] que não cesse de proclamar a verdadeira sabedoria" ( $\mathrm{n}^{2}$ 14). Estas palavras de Boaventura podem escandalizar muitos dos nossos contemporâneos, indignados com a chamada "alienação técnica". Essa indignação agravar-se-ia certamente com outras afirmações do Doutor Seráfico que, além de realçarem o valor estético da obra, vêem nesta um pólo de aprazimento para o autor. Escreve enfaticamente: "[...] in illo delectetur [...] "( $\left.n^{\circ} 14\right)$. Ou ainda: "Com efeito, todo o sentido procura por tendência natural o objecto sensível que the é conveniente, goza [invenit cum gaudio]quando o acha e reitera a sua posse sem tédio, pois que o olho não se farta de ver, nem o ouvido se enche de escutar" ( $\left.n^{2} 10\right)$. É conveniente notar que năo há no Doutor Seráfico qualquer tendência ascética tipificada pelo "contemptus mundi", verificando-se, sim, nele, uma reconciliação total com toda a realídade, ontologicamente sempre positiva e, por isso, experimentada em convívio fratemo. A obra especulativa de Boaventura pode ser justamente considerada a fundamentação filosófica da fratemização franciscana.

22. Será uma ousadia anacrónica o título da obra de J. Gimpel, La Révolution Industrielle du Moyen Âge, Ed. du Seuil, Paris, 1975?

23 "De sorte que sendo cinco os corpos simples do mundo, isto é, os quatro elementos e a quinta essência, para que o homem pudesse perceber todas as formas corporais foi dotado de cinco sentidos correspondentes àqueles" ( $n^{2} 3$ ). A esta doutrina andou associado o modelo microcosmo/macrocosmo, a que nem todos os cristãos aderiram, temendo uma naturalização da vida humana, com evidentes riscos para a liberdade e imortalidade. Boaventura distancia-se já de tais relutâncias. 
senvolvimento dos diversos intervenientes, aliás por apetência da própria realidade sensivel, como adiante se verá.

O mesmo se passa, e sobretudo, com o chamado conhecimento filosófico, "[...] cujo objecto principal se concretiza nas razões formais relativas à matéria, à alma e à sabedoria divina. ${ }^{24}$ Não obstante todo o conhecimento corresponder a uma luz interna, ${ }^{25}$ o conhecimento filosófico é interior por antonomásia, ${ }^{26}$ contrastado com o conhecimento exterior das artes mecânicas, com o conhecimento inferior sensitivo e com o conhecimento superior da Teologia.

É no âmbito desse, o filosófico, que se pode apreciar toda a complexidade da ontologia e da gnosiologia bonaventurianas, bem como o cruzamento harmonizado de influências díspares, designadamente as de proveniência agostiniana, com a iluminação, e aristotélicas, com a abstracção. Se todo o conhecimento é repassado por uma dupla direç̧ão, a horizontal, de relação entre o ser humano e as outras criaturas, e a vertical, mediante a oficina humana, que eleva todos os entes do mundo a instâncias superiores e, em último termo, até Deus, reside sobretudo no poder do conhecimento filosófico este movimento de verticalização gnosiológica, mais esbatida no conhecimento sensitivo e nas artes mecânicas, embora também ai presente. Estabelece-se uma relação dinâmica e também vertical entre diversos patamares ou três ordens de razões, correspondendo estas a uma tríplice forma: as seminais, as abstractas ou intelectuais e as ideais, ${ }^{27}$ obedecedo sempre ao esquema de geração do meio e de relação entre princípio e fim. É deste modo que toda a realidade se desenvolve, até chegar às razões ideais, em Deus, onde tudo começa e onde tudo acaba, mas sem nunca sacrificar a consistência e a diferença ontológicas do meio, que a filosofia grega não preservava, devido à atracção exclusiva da unidade originária indiferenciada e, por assim dizer, egoísta. ${ }^{28}$ Assim se consuma 0 apetite de elevação, intrínseco a todos os entes, também à matéria.

O conhecimento moral, que perfaz o tríptico filosófico, ao lado da filosofia natural e da filosofia racional (lógica), ${ }^{29}$ dispensaria um saber específico, atendendo a que ele corresponde fundamentalmente à realização ontológica de toda a acção, presente em todo o conhecimento, seja de que índole for. No entanto, Boaventura encontrava-o entre todas as classificações legadas pela tradição, determinando, entretanto, o seu objecto e o modo de realização deste com características próprias,

$24 \mathrm{~N}^{2} 19$.

25 "Licet autem omnis illuminatio cognitionis intema sit [...]" ( $\left.n^{2} 1\right)$. "[...] lumen interius, scilicet lumen cognitionis philosophicae" ( $\left.n^{2} 1\right)$.

27 O que importa acima de tudo considerar é a conente de vida que perpassa toda a realidade, envolvendo Deus, sede das razōes ideais (sobre as quais Boaventura reconhece, no $n^{2} 4$, haver controvérsia), o ser humano, sede das razões intelectuais ou abstractas, e os entes materiais, sede das razões seminais $\left(n^{2} 20\right)$. No processo do conhecimento, o entendimento age julgando segundo essas razões, ordenando umas às outras, desde o apetite da matéria, até Deus: "Rursus, appetitus, qui est in materia, ordinatur ad rationes intellectuales [...]" (n² 20). Mas logo acrescenta que a geração năo será perfeita se a alma racional não se unir à matéria (Ibidem). Este desenvolvimento é orientado pela filosofia natural, nas suas diferentes expressões: a fisica ocupa-se das razões seminais, a matemática orienta as razöes intelectuais e a metafisicas remete para o primeiro Principio $\left(n^{2} 4\right)$.

28 As razões ideais são produzidas por Deus, em dinâmica de difusão generosa, em direcção, por assim dizer, eferente e não aferente $\left(n^{2} 20\right)$.

29 "Esta luz [a do conhecimento filosófico] divide-se em racional, natural e moral" ( $n^{\circledR} 4$ ). 
na justiça, entendida como "rectidão da vontade", servindo-se, para o efeito da te. minologia anselmiana. ${ }^{30}$ Evoca, a este propósito, a doutrina grega do justo meio, aproximando-o do esquema cristão da Trindade, distanciando-se decisivamente daquela. ${ }^{31}$ Situado sempre em solo ontológico, insere o Doutor Seráfico a rectidão no processo de expressão, desenvolvimento e elevação dos entes, a começar por Deus, onde há expressão ao mesmo nível ontológico, até às criaturas, nas quais a expressão coincide com a elevação. ${ }^{32}$

Repita-se, uma vez mais, que a justiça referenciada no saber moral se realiza em toda a actividade gnosiológica, traduzindo a orientação correcta da acção que, para ser justa, tem de difundir-se generosamente.

\section{III}

A tomada de consciência da responsabilidade do ser humano perante o universo pode não alterar significativamente 0 contexto antropocêntrico em que a questão do ambiente se tem desenrolado, pois também a esse horizonte humano pertence a categoria da responsabilidade, integre-se esta na esfera ética ou no foro jurídico. Polarizar a questão na responsabilidade significa continuar a ver o ser humano como o centro e senhor do universo, tudo fazendo depender da sua acção. Entregar o futuro do ambiente do nosso planeta à instância de uma responsabilidade, alargada ao universo, equivale a aceitar a continuação do aprisionamento do mundo nas redes dos interesses do ser humano. A obstinação ética do momento actual é um elucidativo sintoma dessa situação. A moral tem representado quase sempre o estatuto de defesa do ser humano, perante as ameaças do outro, não saindo, portanto, do circuito da Antropologia, que já mostrou suficientemente não deter, no seu limitado perímetro, qualquer solução abrangente. Recorre-se, hoje, à Ética ou por falta de alternativa, devido à ausência de alternativas, como a da natureza, do ser ou mesmo da ciência e da técnica, ou por medo. Poder-se-ia afirmar que o egoísmo degradou o ambiente, sendo ainda egoísta a ânsia de o recuperar. A dissolução da referência de natureza e do horizonte ontológico é que possibilitou a entrega dos destinos da realidade a uma suposta autonomia e bondade absolutas da ciência e da técnica, cujos critérios se veriam agora substituídos pelos da Ética. Por outro lado, o arrimo à Ética é, na actualidade, levado a efeito no meio de generalizado pavor e de profunda angústia. A Humanidade está possuída, como nunca, de medo, perante a realidade artificial que ela mesma fabricou. Verdadeiramente, é

30 "O intento da filosofia moral incide principalmente sobre a rectidão, pois o seu objecto é a justiça em geral, a qual, como diz St² Anselmo, é rectidão da vontade" (n² 23).

31 "Em primeiro lugar, diz-se recto aquilo cujo meio não excede os extremos. Ora, sendo Deus a rectidão suma, não só em si mesmo considerado, mas também enquanto é princípio e fim de todas as coisas, necessariamente há-de colocar-se em Deus uma pessoa intermédia da sua mesma natureza" $\left(n^{2} 23\right)$. O meio bonaventuriano, contudo, tem uma função muito diferente da que exercia no esquema grego: "É igualmente necessário colocar um meio na produçăo e no retomo das coisas criadas; mas é indispensável que este meio, no facto da produção, se aproxime mais do producente e, no retomo, se aproxime mais do que retoma". (Ibidem).

32 Não obstante o meio se voltar para as duas direcções, para cima e para baixo, movimento que Cristo praradigmaticamente tipificou, a orientação ontológica, contudo, é para o aito, para o desenvolvimento dos seres:"Em terceiro lugar, diz-se recto aquilo cuja sumidade se ergue para o alto, como quando se diz que é recta a estatura do homem" (n²5). 
de si mesma que a Humanidade receia, espelhando embora esse sentimento no gigantismo da obra produzida.

Será que o pavor perante a ciência e a técnica irá ressuscitar o valor da natureza? Não pululam, por todo o lado, as atitudes e gestos flagrantemente conservadores, que pretendem fazer regressar o estado do universo ao momento originário, recuperando, se possivel, a pureza e o número das espécies que povoavam a Terra na hora adâmica?

Este regresso, a respirar, paradoxalmente, culpabilidade e artifício, poderia ser eventualmente princípio de solução, caso a natureza do real se ajustasse a tal nostalgia. Mas não parece que assim seja. A realidade é dinâmica, estando repassada da intencionalidade de alteração, de aperfeiçoamento histórico. O ser humano não vive na terra ou mesmo no universo, para conservar este, já que supõe transformação constante, em demanda de uma realidade mais una, mais universal e mais diferenciada. A Humanidade vive a terra e o universo, construindo o mundo.

Afinal, do que a Humanidade parece ter medo é da transformação: receio de errar, pavor do risco, desconfiando dos desmandos da sua própria liberdade. Esse pavor, contudo, de natureza psicológica, não se aparenta proporcional à magnitude das suas negativas consequências. O medo da Humanidade é mais abrangente, mais objectivamente determinado. De facto, ela tem medo da realidade, seja esta artificial ou natural. A razão do medo é, pois, mais do que psicológica, é cultural, tem sido alimentado pela cultura, ao menos pelo figurino da cultura ocidental. Esta não vê um sentido para o real, para o múltiplo, para os indivíduos, para a História, para a matéria. Por isso, resta-lhe montar uma estratégia para de tudo isso se libertar. A cultura é isso mesmo, um processo de libertação, em termos literários, uma epopeia. Nesta, a ciência e a técnica têm desempenhado um papel decisivo, ora reduzindo tudo a uma universalidade abstracta, a um objecto, ora transformando os entes, qualitativamente diferenciados, em pura extensão, manipulável, ao sabor dos interesses humanos. A ciência e a técnica ocidentais cumpririam, assim, os desígnios fundamentais da cultura ocidental, indisfarçavelmente maniqueísta e gnóstica. No rendilhado dessa cultura, os factores cristãos não conseguiram irradiar atmosfera envolvente, capaz de convencer do sentido da realidade, do valor da transformação, da diferença, do tempo, onde a ciência e a técnica tivessem uma função insubstituível, mas de sinal diferente daquele que as tem caracterizado.

E, no entanto, nem o movimento do processo da cultura é fatal nem a cultura ocidental tem sido tão uniforme como a necessidade de apressadas sínteses o sugere. Não obstante o próprio cristianismo se ter deixado contaminar, frequentes vezes, pela imperante atmosfera maniqueísta e gnóstica, ele tem representado sempre, ao menos doutrinalmente, um contraponto a essas tendências negativistas.

Redução das Ciências à Teologia é um modelo desse contraponto cristão, com a vantagem de se situar em articulações nevrálgicas, como as da ciência e da técnica.

Aí, pese embora a orientação da verticalidade, o ser humano faz parte do Universo, sem a este se reduzir, mas também sem qualquer prurido de domínio sobre ele; o que caracteriza a acção reciproca dos diversos entes é a relação de amor generoso de ontológica semelhança; de tal modo os riscos de domínio se encontram esbatidos que o ser humano pode comprazer-se na relação com os outros seres, 
designadamente com os sensíveis e com as obras produzidas pelo seu engenho; a matéria não é obstáculo ao exercício do espírito, inclusive ao conhecimento, pois ela é ser, semelhante a todos os outros seres; se não há conflito entre Humanidade/Universo, menos ainda o haverá entre mundo/Deus, transparecendo a realidade divina em toda a acção do mundo; a moral, a rectidão, não é um dever ser construido e imposto extrínseca e artificialmente à naiureza, mas, sim, a expressão da orientação correcta de toda a actividade, tanto mais visivel quanto mais se desenvolve; confiança, e não pavor, trespassa a vida do Universo, tanto a do movimento da natureza como a do fazer das artes mecânicas, que gerarão sempre luz e sentido, desde que constituam acção, e não paixão disfarçada; a realidade é para desenvolver, não para domesticar, mas, nesse processo de manifestação, o critério orientador não será o dos interesses humanos e, sim, o da capacidade das próprias virtualidades do real, até o infinito; não há um esquema arquetípico de espécies a que regressar, não há uma sistemática definitivamente fixada, mas, antes, uma dinâmica de desenvolvimento, apontando para o novo e para o múltiplo.

Neste contexto bonaventuriano, não parece já possivel falar de responsabilidade, mas de fidelidade dinâmica e confiante na luz e na capacidade ordenada de todos os entes. É esta que deve presidir à irrecusável construção do mundo, tarefa constitutiva do ser humano. A Ética, a Ética da responsabilidade, pode constituir o grande logro da Humanidade actual, decorrente da angústia perante um Universo em vias de se tornar aberrante.

A literatura contemporânea não tem sido insensivel a esta mensagem que Boaventura tipificou em Redução das Ciências à Teologia. Um tanto romanticamente, essa literatura tem-na associado ao franciscanismo. Nós diríamos que é cristã, sendo franciscana porque cristã. É ela que Denis de Rougemont vislumbra, em $O$ Amor e o Ocidente, perante os impasses a que o próprio amor conduz. É ainda essa a mensagem de A. Noyes, veiculada na sua deliciosa obra, O Último Homem, onde, no meio da total destruição, remanescem os nus pés franciscanos para calcorrear confiadamente o mundo. É porventura essa a mensagem de $O$ Nome da Rosa de U. Eco, sugerida no meio de impressionantes ambiguidades, onde prepondera a alternativa de um regresso à unidade originária informe ou o despontar de uma reserva verde da terra, que teimosamente emerge, ao lado de uma cultura calcinada por fogo devastador e universal. 